\title{
Long-acting $\beta_{2}$-agonists in adult asthma and the pattern of risk of death and severe asthma outcomes: a study using the GPRD
}

\author{
F. de Vries*, , E. Setakis*, B. Zhang* and T.P. van Staa*\#
}

ABSTRACT: The objective of this study was to describe risks of death and asthma outcomes with prescription of long-acting $\beta_{2}$-agonists (LABA), short-acting $\beta_{2}$-agonists (SABA) or inhaled corticosteroids (ICS) in general practice.

The study population included $\beta_{2}$-agonist users aged $\geqslant 18 \mathrm{yrs}$, who were in the UK General Practice Research Database (GPRD), which is linked to the national registry of hospitalisations. The study included 507,966 patients with 5.5 million SABA, 4.0 million ICS and 1.3 million LABA prescriptions. Rates of asthma outcome increased with more severe treatment steps. The mortality rate was increased with least and most severe treatment steps. Higher relative rates (RR) of outcomes were found in recent starters and heavy long-term users with LABA, SABA and ICS. The RRs in heavy long-term users were 1.9 for all-cause mortality and $\mathbf{3 . 0}$ for asthma death with SABA, 1.4 and 1.6, respectively, with LABA and 1.7 and 2.2, respectively, with ICS. The RR of death was statistically similar over time between LABA and ICS despite changes in exposure.

Risks for death and asthma outcomes varied substantially with exposure characteristics. The statistical power for detecting increases in asthma death was low. The results of this study did not indicate that LABA exposure was associated with an increased risk for all-cause mortality.

KEYWORDS: Asthma, asthma death, $\beta_{2}$-agonists, inhaled corticosteroids

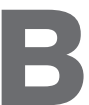
eta $_{2}$-agonists are frequently used drugs in the treatment of asthma. A recent metaanalysis of randomised clinical trials found that long-acting $\beta_{2}$-agonists (LABA) increased life-threatening asthma exacerbations, as well as asthma deaths [1]. However, the study did not address the safety of LABA when used in conjunction with inhaled corticosteroids (ICS) [2]. The results of the meta-analysis also differed from those of two Cochrane reviews, which examined the risk of severe asthma exacerbations requiring hospital admission in patients receiving LABA with ICS $[3,4]$. A recent Cochrane review concluded that LABA are effective in the control of chronic asthma but found that there are potential safety issues which call into question the safety of LABA, particularly in those asthmatics who are not taking ICS [5].

An observational study in actual clinical practice could compare asthma outcomes in patients using $\beta_{2}$-agonists and ICS. However, one of the main challenges in observational research is confounding by indication. The typical approach in observational research is to use regression analyses to deal with this confounding. This is often challenging as information on risk factors may be incomplete. Asthma deaths are highly related to health behaviour and psychosocial factors [6], and reduced use of primary care services [7]. A number of studies have shown that asthma patients are still widely undertreated $[8,9]$, and that poor adherence is associated with poor outcomes [10] and with socioeconomic factors [11]. It is unlikely that sufficient information will be available in epidemiological datasets to deal completely with these biases. But confounding is even more difficult in asthma, since drug exposure is defined by asthma severity, making it very difficult to separate the effect of disease severity from treatment. As an example, treatment guidelines recommend LABA use (together with ICS) in the more severe treatment steps [12], where increased rates of disease-related outcomes are expected.

In this study, a novel approach was developed to describe the patterns of the hazard rates (i.e. absolute risks) of asthma outcomes with changes in exposures. This pattern analysis focuses on convergence or divergence of hazard rates rather than on estimating relative rates (RRs). If two

\section{AFFILIATIONS}

*General Practice Research

Database, Medicines and Healthcare products Regulatory Agency, London, UK, and

\#Utrecht Institute for Pharmaceutical Sciences, Utrecht University, Utrecht, the Netherlands.

CORRESPONDENCE

T.P. van Staa

General Practice Research Database Medicines and Healthcare products

Regulatory Agency

1 Nine Elms Lane

London SW8 5NQ

London

UK

E-mail: Tjeerd.vanstaa@GPRD.com

Received:

Aug 042009

Accepted after revision:

Feb 192010

First published online:

March 292010 
hazard rates are substantially different but remain parallel with changes in exposure, this pattern analysis would suggest a lack of differential effects. The first objective of this study was to describe the patterns of risks of death and asthma outcomes with exposure to different asthma medications in general practice. The second objective of this study was to statistically compare the patterns of risks of death and asthma outcomes between LABA, inhaled short-acting $\beta_{2}$ agonists (SABA) and ICS. It was tested whether the patterns of risk of death and asthma outcomes over time were statistically similar between the various asthma drugs (i.e. whether the RRs were modified with changes in exposure). In addition, it was tested whether the RRs of death and asthma outcomes during current exposure varied between the different asthma medications in patients with similar exposure characteristics.

\section{METHODS}

\section{Data source}

The General Practice Research Database (GPRD) was used for this study. GPRD comprises the anonymised computerised medical records of general practitioners (GPs). GPs play a key role in the UK healthcare system, as they are responsible for primary healthcare and specialist referrals. Patients are affiliated to a practice, which centralises the medical information from the GPs, specialist referrals and hospitalisations. The data recorded in the GPRD include demographic information, prescription details, clinical events, preventive care provided, specialist referrals, hospital admissions and their major outcomes [13]. GPRD currently includes data on $>10$ million patients. GPRD patients in English practices can now be linked individually and anonymously to the national registry of hospital admission (hospital episode statistics, HES). Each hospital records the dates, the admission and the discharge diagnoses of all hospitalisations. HES data were available from 2001 to 2007 for 200 practices. The data from HES and GPRD were recorded and collected independently from each other.

\section{Study population}

The study population consisted of permanently registered patients aged $\geqslant 18$ yrs who received a prescription for inhaled SABA or LABA after January 1, 1993 (asthma guidelines were introduced in this year [14]). The date of the first SABA or LABA prescription after January 1, 1993 was defined as the index date. Patients with codes for chronic obstructive pulmonary disease (COPD) were excluded from the study population (as recorded by the GP in the medical records). A recent validation study in GPRD obtained a $70.3 \%$ sensitivity and $87.7 \%$ specificity for COPD versus asthma diagnosis. The present authors considered this reasonable, given the difficult differential diagnosis of both conditions [15]. In the UK, formoterol and salmeterol are the LABA types used in clinical practice.

\section{Study outcomes}

The period of follow-up was from the index date up to latest GPRD data collection, the patient's transfer out of the practice, or the patient's death, whichever date came first. All prescriptions for different classes of asthma medication following the index date were identified (i.e. inhaled SABAs, oral SABAs, LABAs, xanthines, cromoglycates, leukotriene receptor antagonists, anti-muscarinic bronchdilators, inhaled and oral corticosteroids). The outcomes (after the index date) of interest included death, asthma death and hospitalisation for status asthmaticus (ICD-10 codes J46) as obtained from HES. The cause of death was evaluated using a review of anonymised free text entries at the date of death, as well as a review of the clinical records for appropriate medical codes $\leqslant 21$ days (before and after) of the date of death. This method of classifying cause of death has been used previously in GPRD studies and the distribution of cause of death as classified by this method has been found to be comparable with that of the UK death registry data [16].

\section{Exposure characteristics}

Patients were classified at each prescription for asthma medication according to the following asthma treatment steps (using the management steps of chronic asthma in the British National Formulary which is based on the 2005 guidelines of the British Thoracic Society (BTS) [12]).

1. Inhaled SABA only (no prescription of other asthma medication and at most one oral corticosteroid prescription in the 3 months before).

2. Inhaled SABA and prescribing of either xanthine derivatives, leukotriene receptor antagonists, cromoglycates or standard-dose ICS (no prescription of oral SABA, LABA, or antimuscarinic bronchodilators and at most one oral corticosteroid prescription in the 3 months before). Standard-dose ICS was defined as beclomethasone dipropionate or budesonide $\leqslant 800 \mu \mathrm{g}$ daily or fluticasone propionate $\leqslant 400 \mu \mathrm{g}$ daily, ciclesonide $\leqslant 160 \mu \mathrm{g}$ daily, or mometasone furoate $\leqslant 400 \mu \mathrm{g}$ daily, administered by metered-dose inhaler or powder inhalation device.

3. Standard-dose ICS plus LABA plus inhaled SABA (at most one oral corticosteroid prescription in the 3 months before). The patients could be coprescribed leukotriene receptor antagonists, oral SABA, antimuscarinic bronchodilators and xanthine derivatives.

3b. Standard-dose ICS plus other asthma medication and no LABA (at most one oral corticosteroid prescription in the 3 months before).

3c. LABA and no ICS.

4. High-dose ICS plus LABA (more than one oral corticosteroid prescription in the 3 months before).

4b. High-dose ICS plus other asthma medication and no inhaled SABA or LABA (at most one oral corticosteroid prescription in the 3 months before).

4c. High-dose ICS plus SABA, no LABA

5. Regular use of oral corticosteroids (more than one oral corticosteroid prescription in the 3 months before).

For patients who could not be classified into any of the above treatment steps, their characteristics were reviewed and three additional treatment steps were identified, as follows. 
1. Standard-dose ICS only (no prescribing of other asthma medication and at most one oral corticosteroid prescription in the 3 months before).

2. Standard-dose ICS plus LABA and no SABA.

3. High-dose ICS only (no prescribing of other asthma medication and at most one oral corticosteroid prescription in the 3 months before).

As treatment steps may vary over time, patients were classified in a time-dependent manner with patients moving between steps (up and down) over time. The study population was also classified according to duration of use. First-time users were defined as patients who received the first ever prescription for $\beta_{2}$-agonists $\geqslant 12$ months after start of GPRD data collection.

\section{Patient characteristics}

The age of each patient at the date of the prescription was calculated. In addition, lung function measurements (peak flow rate), where available, were assessed (at the date of the prescription or, if not available, the most recent measurement in the 3 months before).

\section{Pattern of risk over time following a prescription}

We estimated the hazard rates (i.e. absolute risk) over time following prescription. The follow-up period was from the prescription date until the date of the next prescription or the date of censoring, whichever date came first. We evaluated changes in hazard rates over time, i.e. we tested whether rates remained parallel over time or diverged or converged using the test for proportionality in Cox proportional regression (i.e. the interaction between the RR and follow-up time; if this test is not statistically significant, the RR is parallel over time and does not vary with changes in exposure). Proportionality evaluations were used in dose assessments [17] and this approach has been applied previously in a study of the risk of myocardial infarction (MI) in LABA users [18]. In order to estimate the statistical power of the test for proportionality, a series of simulations were conducted using the incidence rates during past exposure and varying the RR during current exposure. This was followed by bootstrapping to identify the lowest RR that could be detected with a statistical power $\beta$ of 0.80 and $\alpha$ of 0.05 .

\section{Pattern of risk with different exposure characteristics}

The rate of outcomes (i.e. number of cases per 100 person-yrs) was estimated during current exposure (i.e. the time within 3 months of a prescription for the asthma medication). These analyses were stratified by exposure characteristics (time since the first prescription and number of prescriptions in the year before) and done separately for inhaled SABA, LABA and ICS. Poisson regression models compared the RRs with different exposure characteristics. Potential confounders in the models included age, sex, calendar yr and comedication. Comedication of each of the subchapters of the British National Formulary was based on prescription in the 6 months before. The regression analyses included those with a prevalence of $\geqslant 5 \%$. None of the analyses were adjusted for any other risk factors or for disease severity. Prior to the start of the study, it was considered likely that the information on risk factors was insufficient to deal with confounding. In all statistical comparisons, patients could move between groups over time (as exposure could change) but were only included in one group at each point in time.

\section{RESULTS}

The study population included 507,966 patients who were followed for an average of 5.0 yrs (median follow-up of $4.2 \mathrm{yrs}$ ). The mean age of the study population was $42.7 \mathrm{yrs}$ and $58.7 \%$ were female. The population received a total of 5.5 million inhaled SABA, 4.0 million ICS, 1.3 million LABA, 425,000 antimuscarinic bronchodilators, 298,000 oral corticosteroids, 260,000 xanthines, 123,000 leukotriene receptor antagonists, 77,000 oral SABA, and 48,000 cromoglycate prescriptions. ICS was prescribed at the same date or in the 3 months before in $60.1 \%$ of the SABA prescriptions and $90.2 \%$ of the LABA prescriptions. LABA was prescribed in $5.7 \%$ of the prescriptions without any ICS prescription in the year before.

Table 1 describes the distribution of treatment steps in the study population and the patient characteristics with each treatment step. Almost half of the prescriptions were provided according to treatment steps 1 or 2 . There were $\sim 900,000$ recordings of peak flow in the study population. The lowest peak flow measurements (in the 3 months prior) were recorded in patients in step 5 (55.6\% of that of step 1$)$ and in step $3 b(65.3 \%)$. Patients in step 1 were least likely to receive any asthma medication in the 6 months after the prescription (73.5\%) and patients in step 5 were more likely to do so $(96.3 \%)$.

Table 2 gives the incidence rates of death, asthma death, hospitalisation for status asthmaticus, and GP visits for asthma exacerbation during current exposure to asthma medication. The rates of the asthma outcomes increased with more severe treatment steps. The mortality rate was associated with treatment steps in a U-shaped manner, with higher risks with treatment steps 1 and 5 . Only $1.9 \%$ of the patients in step 1 had been prescribed an oral corticosteroid in the 3 months before. The rate of death did not change substantially when excluding these patients (rate of 1.9 per 100 person-yrs).

Table 3 shows the incidence rates of death and asthma outcomes during current exposure stratified by exposure characteristics. U-shaped associations were generally found for all-cause death, asthma-related death and hospitalisation for status asthmaticus, with highest risks for patients who started treatment or who were long-term users with very frequent prescribing in the $1 \mathrm{yr}$ before. These U-shaped associations were found during current exposure for LABA, ICS and inhaled SABA but were most pronounced with inhaled SABA. The frequencies of GP visits for asthma exacerbation were generally largest on long-term users and lowest in recent starters of asthma medications.

As shown in table 4, the risks of most outcomes were statistically comparable during current exposure between LABA with and without concomitant prescribing of ICS or SABA (in patients with similar exposure characteristics). Ushaped associations for the risk of death with level of exposure were also found for different combinations of SABA, LABA and ICS. There were no statistically significant increases in the risk of death with LABA compared to SABA only, SABA with other asthma medications (without ICS and LABA), SABA with ICS, and ICS (without SABA and LABA). There was a 


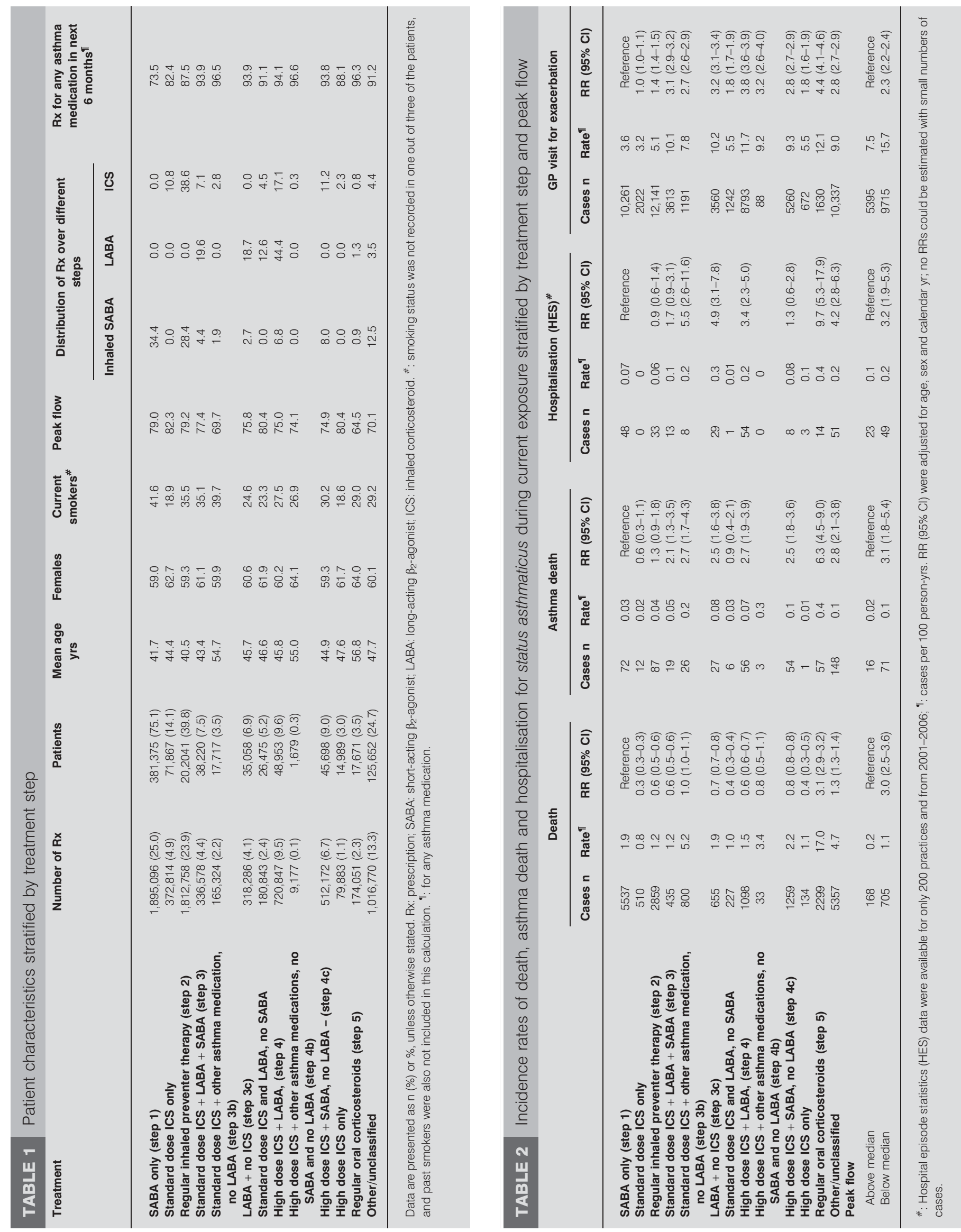


TABLE 3 Relative rates of death, asthma death and hospitalisation for status asthmaticus during current exposure to short-acting $\beta_{2}$-agonists (SABA), long-acting $\beta_{2}$-agonists (LABA) or inhaled corticosteroids (ICS), stratified by exposure characteristics

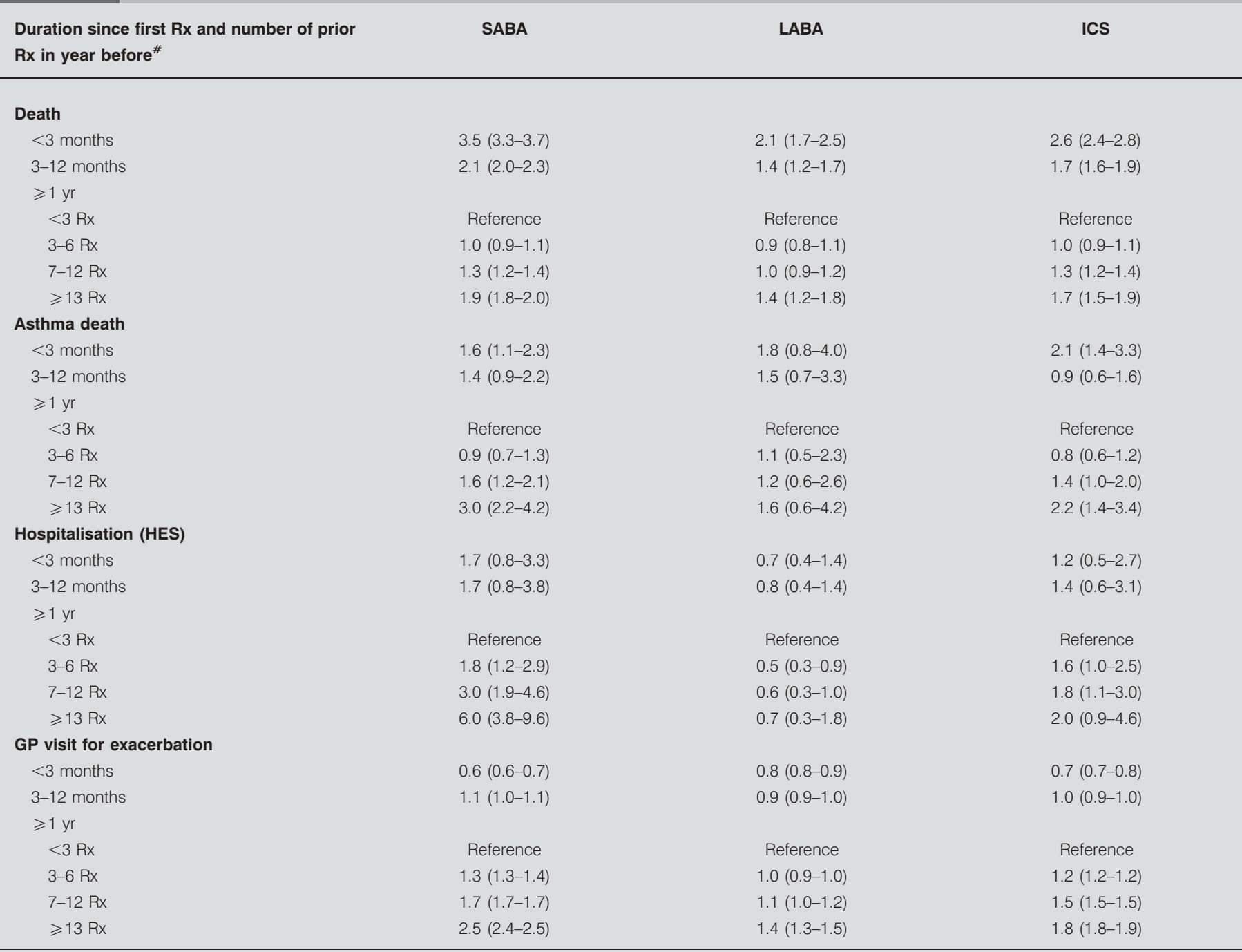

Data are presented as RR (95\% Cl), adjusted for age, sex, calendar yr and comedication; no RRs could be estimated with small number of cases. Rx: prescription; HES: hospital episode statistics; GP: general practitioner. \#: The classification of exposure characteristics was based on the main drug of interest in each column.

considerable overlap in use of different asthma medications in heavy long-term users. Almost half of the heavy long-term SABA users $(47.4 \%)$ had received at least seven ICS prescriptions in the year before; for heavy long-term ICS users, 76.3\% had received at least seven inhaled SABA prescriptions in the year before. Only $48.2 \%$ of the patients who recently started SABA treatment received a prescription for any other asthma medication in the 6 months after (for ICS, this was $70.1 \%$ and for LABA, $88.4 \%$ ). In patients with a long history of use $(\geqslant 5 \mathrm{yrs})$, the percentages with repeat prescribing were 89.1, 91.1 and $94.3 \%$, respectively.

As shown in table 5, the changes over time in the risk of death were statistically comparable between LABA and ICS without LABA (test for proportionality of RR over time $p>0.05$ ). In other words, the RRs between LABA and ICS without LABA were similar during current and past exposure. In contrast,
SABA users without LABA had larger hazard rates during current exposure for death and hospitalisation for status asthmaticus, compared to LABA, with rates converging during past exposure (i.e. the differences between the two groups in the RRs became smaller over time). In this proportionality analysis, the smallest RRs to be detected with a power of 0.80 comparing LABA to SABA without LABA was 1.2 for death, 2.2 for asthma death, 1.2 for GP visits and $>3.0$ for hospitalisations for status asthmaticus. The smallest RRs to be detected with a power of 0.80 comparing LABA to ICS without LABA were $1.2,>3.0,1.2$ and $>3.0$, respectively.

\section{DISCUSSION}

This study found that exposure characteristics such as treatment step and duration and extent of exposure were strongly related to the risk of death and asthma outcomes in 


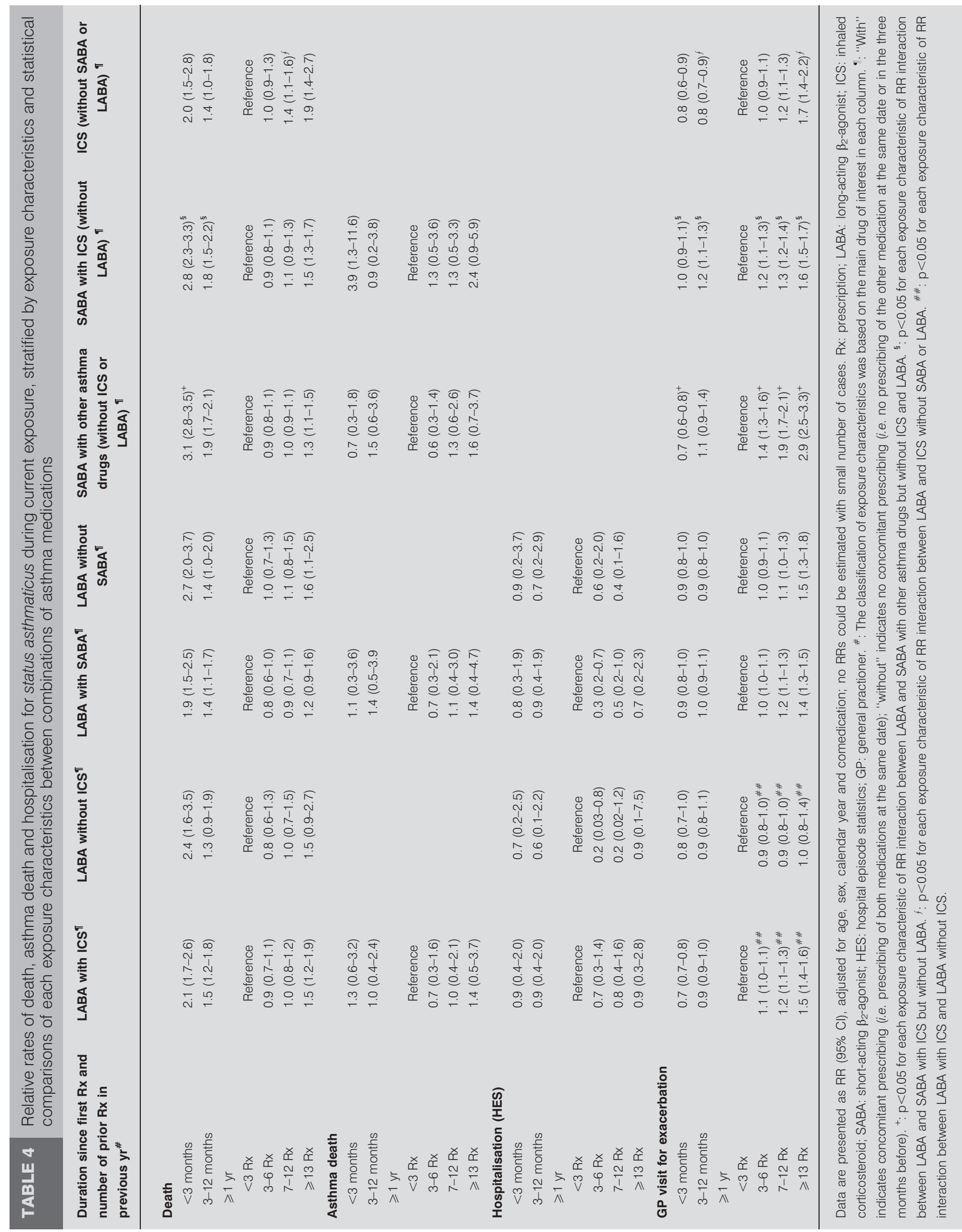




\begin{tabular}{|c|c|c|c|c|c|}
\hline \multirow[t]{2}{*}{ TABLE 5} & \multicolumn{5}{|c|}{$\begin{array}{l}\text { Proportionality }{ }^{\#} \text { of hazard rates over time and the subgroup with the higher relative rates (RR) during current exposure } \\
\text { and lower RR during past exposure comparing different combinations of asthma medications }\end{array}$} \\
\hline & & $\begin{array}{l}\text { LABA versus SABA } \\
\text { without } L A B A^{\pi}\end{array}$ & $\begin{array}{l}\text { LABA versus ICS } \\
\text { without LABA" }\end{array}$ & $\begin{array}{l}\text { LABA without ICS versus } \\
\text { LABA with ICS }{ }^{\pi}\end{array}$ & $\begin{array}{l}\text { ICS with LABA versus } \\
\text { ICS without LABA }\end{array}$ \\
\hline \multicolumn{2}{|l|}{ Death } & SABA without LABA & $=$ & $=$ & $=$ \\
\hline \multicolumn{2}{|c|}{ Asthma death } & $=$ & $=$ & $=$ & $=$ \\
\hline \multicolumn{2}{|c|}{ GP visit for asthma exacerbation } & SABA without $L A B A$ & $=$ & $=$ & $=$ \\
\hline
\end{tabular}

LABA: long-acting $\beta_{2}$-agonist. SABA: short-acting $\beta_{2}$-agonist. ICS: inhaled corticosteroid; HES: hospital episode statistics. ${ }^{*}$ : adjusted for age, sex, calendar year and comedication and stratified by exposure characteristics. ": "with" indicates concomitant prescribing; "without" indicates no concomitant prescribing (i.e. no prescribing of the other medication at the same date or in the three months before). $=:$ RR of hazard rates were statistically proportional ( $p>0.05)$ and RR did not change despite changes in exposure; if there was an interaction between the RR and time $(p<0.05)$, the table lists the subgroup with an increased hazard rate during current exposure

patients using asthma medication. In patients with similar exposure characteristics, there were no major statistically significant increases in the risks of death and asthma outcomes with LABA compared to other asthma drugs. Furthermore, the RRs of these outcomes did not vary statistically with changes in exposure between LABA and ICS.

There are various limitations to this study. The approach in this study was to describe the patterns of hazard rates. Rather than testing a specific hypothesis, this study described and explored the outcomes in multiple subgroups of patients using SABA, LABA or ICS in relation to exposure characteristics. These subgroup analyses allowed for unusual results in some of the subgroups due to random variation. However, this study may have lacked statistical power for the analysis of the rare outcomes (such as asthma death) in some of the subgroups.

Another limitation was that information on confounders was limited to age, sex and calendar yr and this was decided prior to conducting the study given the limited ability to correct for confounding. A randomised trial could of course prevent this confounding. However, randomised trials typically require that the exposure to asthma medication is well controlled and more homogenous between patients, while drug exposure in actual clinical practice often varies greatly, with different drug combinations and patients switching between drugs. Our study utilised this heterogeneity in drug exposures, evaluating the pattern of risks with changes in exposure. A limitation of this approach is that the analysis of patterns is unable to detect any effects which consistently occur with all asthma treatments. Also, drug effects which persist for a long period of time after drug discontinuation would not be detected with an evaluation of patterns of risk with changes in drug exposure. Another limitation was that the exposure information was based on prescription information rather than on actual use by patients. Patients in different treatment steps may have had varying levels of compliance due to different psychosocial characteristics. Lack of information on prescribing from hospital clinics in which more severe patients may be treated is another limitation. The treatment step of ICS and LABA but no SABA may have included patients who used LABA as the reliever medication, and the treatment step with ICS only may have included patients who were not using SABA because their asthma was well controlled. We could not measure these using the GPRD. This study (and other published studies) may have a further limitation in its statistical power to detect small but clinically meaningful increases in risk due to the low frequency of asthma-related deaths. A meta-analysis of $\sim 50,000$ formoterol-treated subjects only recorded eight asthma-related deaths [19]. Increases in risks that are restricted to particular subgroups of patients (such as heavy long-term use) may also be difficult to detect statistically due to the lower frequency.

An observational study in actual clinical practice could compare asthma outcomes in patients using $\beta_{2}$-agonists and ICS. However, one of the main challenges in observational research is confounding by indication. The typical approach in the observational research is to use regression analyses in order to deal with this confounding. This is often challenging as information on risk factors may be incomplete. But confounding is even more difficult in asthma, since drug exposure is defined by asthma severity, making it very difficult to separate the effect of disease severity from treatment. As an example, treatment guidelines recommend LABA use in treatment steps 3-5, where increased rates of disease-related outcomes are expected [12]. In our pattern analysis, systematic differences between two groups due to confounding are not a concern, as the analysis focuses on convergence or divergence of hazard rates rather than on estimating RRs. In the case of two rates that are substantially different but that remain parallel, the pattern analysis would find a lack of effect, while the standard epidemiological analysis would find a RR different from unity. In this study, time-dependent changes in RRs over time were assessed using the standard test for proportionality in Cox regression. However, an important limitation of this pattern analysis, also present in standard epidemiological analyses, is bias by time-dependent confounding (i.e. differential changes over time in risk factors or asthma severity).

A recent meta-analysis concluded that LABA increased the risk of severe and life-threatening asthma exacerbations and asthma deaths [1]. In most of the studies that were used by ERNST et al [2], patients were not required to take ICS. The very large Salmeterol Multicentre Asthma Research Trial found an increased risk of asthma deaths in patients taking the LABA salmeterol compared to placebo. About half of the study patients did not use ICS at baseline [20]. However, ICS use was 
not recorded during the study period. A recent Cochrane review concluded that there was no evidence that underlying control of asthma deteriorates with regular LABA use with concomitant ICS use [5]. A meta-analysis of 20,000 patients randomised to ICS plus salmeterol or ICS only found no difference in the rate of asthma-related hospitalisations [21]. An analysis of the safety data collected in clinical trials of formoterol found no increase with formoterol in serious asthma-related adverse events (mostly hospitalisations) [19]. In the present study, there were no major statistically significant increases in the risks of outcomes with LABA compared to other asthma drugs in patients with similar exposure characteristics. We also found that the RRs were statistically proportional between LABA and ICS over time, despite changes in exposure. With any differential effects between these drugs, it would be expected that the risks would diverge with changes in exposure.

Several studies have evaluated asthma death in patients using asthma medication [22-36]. In the present study, a U-shaped association was found between the risk of asthma death and the time since the first prescription and number of prescriptions in the year before, with higher risks in recent starters and heavy long-term users. This U-shaped association occurred with all the asthma outcomes measured in this study (asthma death, GP visits for asthma exacerbations and hospitalisations for status asthmaticus). This U-shaped association was also present in inhaled SABA users, and in ICS and LABA users. Heavy use of inhaled SABA has been associated in other studies with an increased risk of asthma death [29, 34]. In contrast, two Canadian case-control studies reported that regular ICS users had a reduced risk of asthma death compared to non-users [27, 32]. But these case-control studies lacked statistical power to detect any increase in the risk of asthma death in heavy long-term ICS users and no information on the risks in heavy long-term ICS users was reported. For LABA, a UK case-control study did not find evidence of adverse effects on asthma mortality, although no estimates were provided for heavy long-term users separately [35]. Another study found that LABA was not associated with a significantly increased risk of near-fatal asthma attacks [36]. Heavy long-term users of asthma medication had higher rates of oral corticosteroid prescribing in the year before with any type of asthma drug, suggesting the presence of severe unstable asthma, requiring very frequent and unusual levels of prescribing. In addition to this major confounding, the considerable overlap in use of different asthma medications in heavy longterm users further complicates the disentanglement of the individual effects of the various classes of asthma drugs.

The risks of death were found to be U-shaped, with highest risks in patients with the least and most severe treatment steps (steps 1 and 5). The increased risks in step 5 are expected, given the more severe underlying disease. Peak flow measurements were on average lowest in step 5. But this does not explain the higher risks in step 1, as peak flow was highest in this group of patients. Some patient characteristics were different in step 1, such as smoking history. A substantive proportion of patients in step 1 also did not receive any further asthma medication. Interestingly, a recent study in the same population also found a U-shaped distribution of cardiovascular risks, with higher risks in step 1 [18]. A possible explanation for the higher risks in step 1 is that asthma medication was prescribed for nonasthmatic dyspnoea (such as heart failure). Alternatively, inhaled SABA may have been prescribed to some patients in order to investigate a differential diagnosis, with asthma as the diagnosis if the patient responded. This further complicates the causal interpretation of these findings.

In conclusion, there was a considerable heterogeneity in how patients were exposed to asthma medication. Risks for allcause and asthma death varied substantially with these exposure characteristics. The statistical power for detecting increases in asthma death was low in this study.

The results of this study of adult patients with asthma in GPRD did not indicate that LABA exposure was associated with an increased risk for all-cause mortality.

\section{SUPPORT STATEMENT}

The study was funded by AstraZeneca. The senior author of this publication wrote the protocol that was reviewed by AstraZeneca, the independent scientific advisory group (ISAC) of GPRD and the Division of Vigilance and Risk Management of Medicines of the Medicines and Healthcare products Regulatory Agency (MHRA). The study sponsor had no role in the data analyses. With funded research projects, GPRD contractually retains the right to publish the data. GPRD is owned by the UK Department of Health and operates within the Medicines and Healthcare products Regulatory Agency (MHRA). GPRD is funded by the MHRA, the Medical Research Council, various universities, contract research organisations and pharmaceutical companies. The study was initiated for a regulatory review of the safety of LABA. The views expressed in this paper are those of the authors and do not reflect the official policy or position of the MHRA.

\section{STATEMENT OF INTEREST}

A statement of interest for the present study can be foud at www.erj. ersjournals.com $/ \mathrm{misc} /$ statements.dtl

\section{REFERENCES}

1 Salpeter SR, Buckley NS, Ormiston TM, et al. Meta-analysis: effect of long-acting $\beta$-agonists on severe asthma exacerbations and asthma-related deaths. Ann Intern Med 2006; 144: 904-912.

2 Ernst P, McIvor A, Ducharme FM, et al. Safety and effectiveness of long-acting inhaled $\beta$-agonist bronchodilators when taken with inhaled corticosteroids. Ann Intern Med 2006; 145: 692-694.

3 Ni Chroinin M, Greenstone IR, Danish A, et al. Long-acting $\beta_{2}-$ agonists versus placebo in addition to inhaled corticosteroids in children and adults with chronic asthma. Cochrane Database Syst Rev 2005; 19: CD005535.

4 Greenstone IR, Ni Chroinin MN, Masse V, et al. Combination of inhaled long-acting $\beta_{2}$-agonists and inhaled steroids versus higher dose of inhaled steroids in children and adults with persistent asthma. Cochrane Database Syst Rev 2005; 19: CD005533.

5 Walters E, Gibson P, Lasserson T, et al. Long-acting $\beta_{2}$-agonists for chronic asthma in adults and children where background therapy contains varied or no inhaled corticosteroid. Cochrane Database Syst Rev 2007; 24: CD001385.

6 Sturdy PM, Victor CR, Anderson HR, et al. Psychological, social and health behaviour risk factors for deaths certified as asthma: a national case-control study. Thorax 2002; 57: 1034-1039.

7 Sturdy PM, Butland BK, Anderson HR, et al. Deaths certified as asthma and use of medical services: a national case-control study. Thorax 2005; 60: 909-915. 
8 Rabe KF, Vermeire PA, Soriano JB, et al. Clinical management of asthma in 1999: the Asthma Insights and Reality in Europe (AIRE) study. Eur Respir J 2000; 16: 802-807.

9 Partridge MR, van der Molen T, Myrseth SE, et al. Attitudes and actions of asthma patients on regular maintenance therapy: the INSPIRE study. BMC Pulm Med 2006; 6: 13.

10 Williams LK, Pladevall M, Xi H, et al. Relationship between adherence to inhaled corticosteroids and poor outcomes among adults with asthma. J Allergy Clin Immunol 2004; 114: 1288-1293.

11 Apter AJ, Reisine ST, Affleck G, et al. Adherence with twice-daily dosing of inhaled steroids. Socioeconomic and health-belief differences. Am J Respir Crit Car Med 1998; 157: 1810-1817.

12 British Thoracic Society, Scottish Intercollegiate Guidelines Network. British guideline on the management of asthma. www. brit-thoracic.org.uk/Portals/0/Clinical\%20Information/Asthma/ Guidelines/asthmaupdatenov05.pdf Date last accessed: July 1, 2008. Date last updated: November 2005.

13 Parkinson J, Davis S, van Staa TP. The General Practice Research (GPRD) Database: now and the future. In: Pharmacovigilance. $\mathrm{R}$ Mann, ed. Chichester, John Wiley \& Sons, 2007; pp. 341-348.

14 British Thoracic Society, British Paediatric Association, Royal College of Physicians, et al, Guidelines on the management of asthma. Thorax 1993; 48: S1-S24.

15 Soriano JB, Maier WC, Visick G, et al. Validation of general practitioner-diagnosed COPD in the UK General Practice Research Database. Eur J Epidemiol 2001; 17: 1075-1080.

16 Shah AD, Martinez C. A comparison of the cause of death recorded in the General Practice Research Database with national mortality statistics in England and Wales. Pharmacoepid Drug Saf 2004; 13: S2-S3.

17 Smith BP, Vandenhende FR, DeSante KA, et al. Confidence interval criteria for assessment of dose prportionality. Pharmaceutical Research 2000; 17: 1278-1283.

18 Zhang B, de Vries F, Setakis E, et al. The pattern of risk of myocardial infarction in patients taking asthma medication: a study with the General Practice Research Database. J Hypert 2009; 27: $1485-1492$.

19 Sears MR, Ottosson A, Radner F, et al. Long-acting $\beta$-agonists: a review of formoterol safety data from asthma clinical trials. Eur Respir J 2009; 33: 21-32.

20 Nelson HS, Weiss ST, Bleecker ER, et al. The Salmeterol Multicenter Asthma Research Trial: a comparison of usual pharmacotherapy for asthma or usual pharmacotherapy plus salmeterol. Chest 2006; 129: $15-26$.

21 Bateman E, Nelson H, Bousquet J, et al. Meta-analysis: effects of adding salmeterol to inhaled corticosteroids on serious asthmarelated events. Ann Intern Med 2008; 149: 33-42.
22 Crane J, Pearce N, Flatt A, et al. Prescribed fenoterol and death from asthma in New Zealand, 1981-83: case-control study. Lancet 1989; 1: 917-922.

23 Pearce N, Grainger J, Atkinson M, et al. Case-control study of prescribed fenoterol and death from asthma in New Zealand, 1977-81. Thorax 1990; 45: 170-175.

24 Grainger J, Woodman K, Pearce N, et al. Prescribed fenoterol and death from asthma in New Zealand, 1981-7: a further case-control study. Thorax 1991; 46: 105-111.

25 Woodman K, Pearce N, Beasley R, et al. Albuterol and deaths from asthma in New Zealand from 1969 to 1976: a case-control study. Clin Pharmacol Ther 1992; 51: 566-571.

26 Spitzer WO, Suissa S, Ernst $P$, et al. The use of $\beta$-agonists and the risk of death and near death from asthma. N Engl J Med 1992; 326 501-506.

27 Ernst P, Spitzer WO, Suissa S, et al. Risk of fatal and near-fatal asthma in relation to inhaled corticosteroid use. JAMA 1992; 268: 3462-3464.

28 Castle W, Fuller R, Hall J, et al. Serevent nationwide surveillance study: comparison of salmeterol with salbutamol in asthmatic patients who require regular bronchodilator treatment. BMJ 1993; 306: 1034-1037.

29 Suissa S, Ernst P, Boivin JF, et al. A cohort analysis of excess mortality in asthma and the use of inhaled $\beta$-agonists. Am J Respir Crit Care Med 1994; 149: 604-610.

30 Meier CR, Jick H. Drug use and pulmonary death rates in increasingly symptomatic asthma patients in the UK. Thorax 1997; 52: 612-617.

31 Guite HF, Dundas R, Burney PG. Risk factors for death from asthma, chronic obstructive pulmonary disease, and cardiovascular disease after a hospital admission for asthma. Thorax 1999; 54: 301-307.

32 Suissa S, Ernst P, Benayoun S, et al. Low-dose inhaled corticosteroids and the prevention of death from asthma. N Engl J Med 2000; 343: 332-336.

33 Martin RM, Shakir S. Age- and gender-specific asthma death rates in patients taking long-acting $\beta_{2}$-agonists: prescription event monitoring pharmacosurveillance studies. Drug Saf 2001; 24: 475-481.

34 Lanes SF, García Rodríguez LA, Huerta C. Respiratory medications and risk of asthma death. Thorax 2002; 57: 683-686.

35 Anderson HR, Ayres JG, Sturdy PM, et al. Bronchodilator treatment and deaths from asthma: case-control study. BMJ 2005; 330: 11-77.

36 Williams C, Crossland L, Finnerty J, et al. Case-control study of salmeterol and near-fatal attacks of asthma. Thorax 1998; 53: 7-13. 